\title{
¿PUEDE LA INTERVENCIÓN ESTATAL SER JUSTIFICADA CIENTÍFICAMENTE? UNA CRÍTICA
}

\author{
MIGUEL ANXO BASTOS BOUBETA*
}

Resumen: El objeto de este artículo es tratar de demostrar que las justificaciones de la necesidad del Estado basadas en la ciencia económica no pueden ser sostenidas. Ni las externalidades ni los fallos del mercado son suficientes para justificar la intervención estatal. Ésta tendrá que recurrir a argumentos extraeconómicos basados en la tradición, el miedo o la historia para justificarse, pero no a la ciencia económica.

Palabras clave: Intervencionismo, externalidades, fallos del mercado, economía austriaca, origen del Estado.

Abstract: The intention of this paper is to demonstrate that the need of the state justifications based on economic reasons cannot be sustained. Neither externalities, nor market failures are sufficient to justify government's intervention. Interventionism must be justified by fear, tradition or history, but never by the economic science.

Key words: Interventionism, externalities, market failures, Austrian economics, origin of the State.

Clasificación JEL: E61, E62, E63.

* Fac. de Ciencias Políticas e Sociais, Campus Sur, Universidade de Santiago de Compostela (A Coruña).

Procesos de Mercado: Revista Europea de Economía Política Vol. II, n. ${ }^{\circ}$ 1, Primavera 2005, pp. 11 a 51 
«La teoría social elemental muestra, en contra de la opinión dominante en estos asuntos, que ningún Estado tiene justificación económica o ética. Todo Estado, independientemente de su constitución, es económica y éticamente deficiente».

(Hans-Hermann Hoppe)

\section{INTRODUCCIÓN}

El lector que afronte la lectura de cualquier manual o libro sobre análisis de políticas públicas se encuentra, en la práctica totalidad de los casos, con que la oportunidad de la intervención estatal reguladora, incentivadora o sancionadora en la vida social y económica se da por supuesta sin ser jamás objeto de discusión. Ya hablemos de políticas laborales, medioambientales, de género o de normalización lingüística, el común de los analistas de políticas no sólo no se molesta en discutir la necesidad de la actuación imperativa del Estado, nunca cuestionada, sino que cuando hace recomendaciones o propuestas de política, en la inmensa mayoría de las ocasiones, reclama una intervención estatal aún mayor ${ }^{1}$. Dos razones podrían explicar

1 En este artículo vamos a referirnos de forma indistinta a todas las políticas públicas, no considerando pertinente distinguir entre políticas económicas o no económicas por dos razones. Primero, porque toda política pública, sea o no económica, implica siempre cierto grado de coerción sobre el uso legítimo de algún derecho de propiedad (esto es siempre que no se agreda los derechos legítimos de otra persona). Esta coerción puede ser directa, sobre el derecho al disfrute de la propiedad de nuestro propio cuerpo (servicio militar, prohibición de determinadas conductas, consumos $\mathrm{u}$ oficios...) o de nuestros bienes legítimamente adquiridos (controles de precios, restricciones al comercio de determinados bienes...), o indirecta, a través de la requisa forzosa del fruto de nuestra actividad o de nuestros bienes a través de impuestos para financiar las actividades estatales. En segundo lugar, y relacionado con lo anterior, porque toda intervención estatal altera coercitivamente la estructura de preferencias de los actores y, por tanto, altera la estructura de precios relativos que se produciría en ausencia de coerción y, por ello, tiene implicaciones económicas más allá del objetivo procurado (el servicio militar altera el mercado de trabajo; la prohibición de la droga eleva su precio, genera rentas de escasez a favor de sus vendedores y puede llegar a distorsionar la estruc- 
esta predisposición a la intervención entre los practicantes del análisis de políticas. La primera se derivaría de la existencia de un corpus teórico elaborado que justifica y legitima las políticas de intervención estatal al dotarlas de un aura de cientifici$\mathrm{dad}^{2}$ (al que nos referiremos en este artículo). La segunda se derivaría de la propia naturaleza de estos estudios. El origen y la evolución de los estudios de políticas públicas están estrechamente ligados al gobernante. Bien como sancionador, bien como legitimador de sus actuaciones, siempre a lo largo de la historia ha estado a sueldo del gobierno. El apogeo reciente de tales estudios se debe, según sus historiadores ${ }^{3}$ (Goldhamer, 1978), a la conjunción de una creciente demanda de análisis político derivada del espectacular incremento en tamaño y funciones del Estado desde los 60 hasta nuestros días, con la proliferación de técnicas de análisis sofisticadas elaboradas por los planificadores sociales y con una mentalidad tecnocrática y racional-constructivista que otorga a gobernantes y planificadores la legitimidad para diseñar los procesos sociales. Así, los políticos demandan análisis y argumentos en la elaboración y justificación de sus decisiones de política, ya de forma previa a la toma de decisiones, para mejorar la calidad de las mis-

tura de naciones enteras; los controles de precios generan escasez; el incremento del gasto público puede producir inflación y alterar artificialmente la estructura de precios...). Por tanto, no es fácil distinguir entre política económica y no económica. Más bien podemos decir que toda política pública es política económica en el sentido de que tiene algún tipo de incidencia en la vida económica y que toda política económica es política en sentido general, pues altera la estructura de preferencias, y por tanto el comportamiento de los ciudadanos a través del uso de la coerción estatal sin la cual no podría ser llevada a cabo.

2 Una introducción a esta temática desde una perspectiva austriaca puede encontrarse en Robert Formaini (Formaini, 1990).

3 En este libro, Goldhamer historia la figura del analista de políticas y subraya la continuidad histórica entre brujos y hechiceros, justificando su labor en la interpretación de libros y fórmulas mágicas, no accesibles por su retorcido lenguaje al mortal común, y los modernos expertos económicos, que harían más o menos lo mismo. Sobre el origen de las modernas disciplinas de análisis de políticas, ver también Torgeson (1999), Boix (1991) y Garzón (1992). 
mas, ya a posteriori (procedimiento este último que acostumbra a ser el más frecuente), para justificar y legitimar públicamente las decisiones previamente adoptadas.

La venalidad del análisis de políticas a la clase gobernante, junto con el no cuestionamiento de la legitimidad de la intervención política y la interesada defensa de la necesidad de nuevas intervenciones, explican la popularidad del análisis de políticas públicas entre la susodicha clase ${ }^{4}$. Pero que una disciplina sea venal e interesada no implica que se deba cuestionar la validez de sus argumentos. En efecto, que un argumento sea formulado por razones nobles o espurias no altera la validez lógica de sus postulados, sólo explica la ausencia de críticas a los mismos o el ocultamiento en la exposición de razonamientos críticos. Este artículo tratará de esbozar las principales críticas realizadas a los argumentos favorables a la existencia de políticas públicas, tanto en su aspecto cataláctico como éticofilosófico; y siempre teniendo en cuenta que en el mundo del análisis de políticas públicas, como de la ciencia política en general, no existe (por las razones antes apuntadas y también probablemente por desconocimiento) oposición teórica a la existencia de aquello que justifica nuestro oficio de analistas de políticas. Si el deseo manifiesto de Keynes (Keynes, 1988) era asimilar el papel del economista con el de un dentista que, gracias a sus herramientas y a sus saberes, resuelve de forma expeditiva los problemas que le encomiendan, el mío es que el papel del analista de políticas llegue a ser algún día el de un especialista en patologías que trabaja para descubrir bacilos y virus y desarrollar vacunas que los prevengan y combatan, y esto aun a sabiendas de que, de darse su triunfo final, podría quedar sin ocupación.

${ }^{4}$ Es interesante recordar aquí que buena parte de los teóricos austriacos comparten la visión, expresada ya hace tiempo por Calhoun (1851) y Oppenheimer (1926), de una sociedad dividida entre una clase explotadora minoritaria, beneficiaria de la coerción estatal, y una explotada, que padece tal coerción. Es un aná- 


\section{LA NECESIDAD DE JUSTIFICAR \\ LA ACTIVIDAD GUBERNAMENTAL: ARGUMENTOS A FAVOR DE LA INTERVENCIÓN}

La intervención coercitiva en la vida económica y social es indisoluble de la existencia del Estado ${ }^{5}$. Éste, independientemente de la visión más o menos benévola que tengamos de las razones que motivaron su existencia, nunca se limitó, salvo raras excepciones, a la labor de mantener el orden, la justicia y el respeto por los derechos de propiedad, sino que siempre manifestó una especial predilección por intervenir y regular la vida de sus ciudadanos y, muy especialmente, los aspectos relativos a la vida económica y comercial, porque es ahí donde se encuentran los medios necesarios para su sostenimiento y porque el control de la vida económica implica el control de una de las principales fuentes del poder social ${ }^{6}$. Lo que se pretende decir es que la intervención nace con el Estado y que las formas que ésta adopta evolucionan a la par que éste. Los impuestos, la manipulación de la moneda y el crédito, las regulaciones del comercio y los precios, así como las ideas que buscan su justificación, existen desde que existen los gobiernos. Si rebuscamos en los tratados antiguos del arte de gobernar (espejos de príncipes, arbitrios...) nos encontramos con muy pocas diferencias respecto de hoy en día en lo que se refiere a las medidas intervencionistas adop-

lisis similar al marxista, sólo que la explotación no se deriva de la posesión de medios de producción, sino de la posesión de los medios de coerción estatales. Ver también al respecto Hoppe (1990).

5 Cuando hablo del Estado me refiero, por supuesto, a las personas que lo dirigen. El Estado como tal no existe, son personas organizadas y jerarquizadas, vinculadas por relaciones jurídicas y de poder, que operan sobre un territorio monopolizando el uso de la fuerza.

6 Esto no implica que todos los gobiernos hayan intervenido con la misma intensidad a lo largo de la historia. El grado de desregulación de la vida económica durante el siglo XX, tanto en las repúblicas socialistas como en las modernas democracias, no tiene parangón en la historia. Sobre la diferencia de la intervención entre monarquías y regímenes democráticos, ver Hoppe (2001). 
tadas por los gobernantes. La diferencia fundamental reside en que estas medidas se justificaban, bien para el sostenimiento y engrandecimiento del reino, bien por oscuras, oportunistas y nunca desveladas razones de Estado, y se transmitían de forma tácita entre los involucrados en las tareas de gobierno sin llegar a formularse nunca una justificación «científica» de su necesidad. El gobernante actual, por su parte, actúa con las mismas motivaciones e intereses que los anteriores, sólo que, por una parte, su campo de intervención es mucho mayor, tanto en la cantidad de ámbitos que están bajo su jurisdicción como en su capacidad real de incidir efectivamente en ellos, y, por otra, como consecuencia de lo anterior, la legitimidad de su actuación ya no se busca en la tradición o en la voluntad popular, sino en la complejidad técnica de la gestión de los negocios públicos actuales, estando, por tanto, los gobernantes legitimados ahora en buena medida por su capacidad de gestión técnica de los negocios públicos. La principal consecuencia de esta legitimación técnica de la actuación política es que las viejas justificaciones tradicionales o morales de la actividad estatal ya no son pertinentes, haciéndose necesario para los modernos administradores públicos proceder a desarrollar justificaciones teóricas adecuadas a las nuevas formas de legitimidad.

La ciencia económica actual (al menos en los paradigmas dominantes keynesianos y neoclásicos) ${ }^{7}$, una vez que pretende también legitimarse como "científica» imitando los métodos

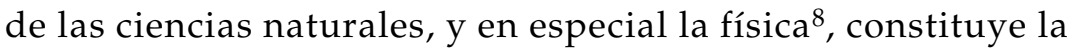

7 Sobre las similitudes entre la obra de Friedman y el keynesianismo, se puede consultar Rothbard (2002), Huerta de Soto (2000), Biddle y Samuels (2002) y Aranzadi del Cerro (1999).

8 En efecto, la economía imita a la física en sus métodos y en sus pretensiones de obtener el mejor rendimiento posible de un sistema. Ambos coinciden en sus pretensiones de optimizar recursos y en la idea de que puede descubrirse una solución óptima a un determinado problema. Los economistas denominan a esta solución óptima «equilibrio» y orientan todas sus ecuaciones y funciones mate- 
compañera ideal del moderno gobierno tecnocrático ${ }^{9}$. Los economistas «oficiales» keynesianos y neoclásicos, al aliarse con el gobierno, ganarían reconocimiento como expertos, consiguiendo influencia en la elaboración de políticas y puestos en el gobierno ${ }^{10}$; a cambio, ellos legitimarían científicamente la intervención estatal permitiendo a los actores estatales incrementar el ámbito y alcance de su poder y su capacidad de influencia. Veamos ahora cuáles son los principales argumentos que se han desarrollado para tratar de justificar la intervención pública.

\section{Argumentos de orden cataláctico}

Tratan de justificar la intervención basándose principalmente en los fallos e imperfecciones del mercado con respecto a una suerte de modelo ideal del mismo caracterizado por una situación de equilibrio, de información y competencia perfecta, un mundo ideal de pequeñas empresas y granjas compitiendo entre sí en igualdad de condiciones, regidas todas por el imperativo de la eficiencia ${ }^{11}$. Como el mundo real no se amolda a estas condiciones, los teóricos de los fallos del mercado achacan al mercado una serie de disfunciones que un gobierno bueno y bien intencionado se encargará de corregir por el bien del

máticas hacia ese ideal. El problema es que la economía es una ciencia de la acción humana, mientras que la física trata con objetos desprovistos de voluntad (Mirowski, 1989; Huerta de Soto, 2004; Hayek, 2003).

9 La necesidad cada vez mayor de justificar en conocimientos científicos la legitimidad del ejercicio del poder puede verse en Gouldner (1985).

10 El fenómeno del aumento del poder tecno-burocrático puede observarse en el incremento de los requisitos de conocimiento para el acceso a numerosos cargos antes políticos (en la Administración española, por ejemplo, se requieren cada vez en mayor medida títulos universitarios para el acceso a altos cargos) o incluso en la reserva para determinados cuerpos de especialistas de los altos cargos estatales (Peters, 1999).

11 Una crítica al principio de la eficiencia como principio justificador de la intervención puede verse en Rothbard (1979). 
propio mercado. Varias son las concreciones de esta argumentación.

Destaca, en primer lugar, la teoría de los bienes públicos, al menos tal como es formulada por Samuelson ${ }^{12}$ (Samuelson, 1954, 1955). Según esta teoría, existirán una serie de bienes, denominados «bienes públicos», dotados de dos características: su consumo conjunto, esto es, que su consumo por un individuo no excluye el consumo de otros, al mismo tiempo que el consumo de un individuo adicional no afecta al coste de producción del servicio, y la no exclusión, esto es, la imposibilidad de excluir a nadie de su disfrute. Bienes como la defensa, el alumbrado eléctrico o los faros serían ejemplos de este tipo de bienes. Según Samuelson, estos bienes sería infraproducidos o no producidos en absoluto, ya que nadie querría pagarlos al poder tener acceso a ellos gratuitamente una vez producidos, siendo necesaria, por tanto, la intervención estatal coactiva a través de impuestos o prestaciones personales forzosas para que lleguen a ser producidos.

En segundo lugar, podríamos apuntar como justificación de la intervención estatal toda la teoría de los fallos del mercado. Como antes apuntamos, los defensores de la intervención parten de una visión ideal, estática y eficientista de los procesos de mercado, culpando a fuerzas inherentes al propio mercado de las desviaciones de ese ideal y siendo, por tanto, necesario corregir coactivamente tales disfunciones. Destacan varios argumentos dentro de esta categoría:

12 Samuelson popularizó estas ideas gracias a sus enormemente populares manuales de economía, que, solos o en colaboración, conformaron las ideas de miles de académicos y estudiantes de ciencias sociales en todo el mundo, dándoles un sesgo estatista a su educación. Así, académicos como Musgrave o Buchanan incorporaron estos argumentos a sus análisis, dando por sentada la necesidad económica del Estado. Una visión crítica desde la perspectiva austriaca puede encontrarse en Block $(1989,1993)$. 
a) Asimetrías de información

Partiendo de la idea de que la información en el mercado debe ser perfecta, los partidarios de la regulación estatal afirmarán que ésta es necesaria para evitar abusos por parte de los actores más informados o más expertos, mediante el establecimiento de regulaciones de todo tipo (estándares de calidad, licencias de apertura, controles de precios...) para tratar de igualar la información de todos los participantes en el mercado.

\section{b) Externalidades}

Son costes o beneficios que las actividades del mercado ocasionan pero que no se repercuten en el precio. Se incide especialmente por los partidarios de la intervención estatal en la necesidad de que los causantes de costes externos, como ruidos, polución, congestiones de tráfico o daños estéticos, repercutan estos costes, bien sobre los consumidores directos, bien sobre la sociedad en su conjunto, siendo los poderes públicos los encargados de garantizar el resarcimiento. Curiosamente, no se propone por parte de los intervencionistas la postura contraria, esto es, que los productores de externalidades positivas, como construir casas hermosas que mejoren el vecindario, puedan cargar precios a sus beneficiarios.

\section{c) Monopolios y competencia imperfecta}

Este presunto fallo, en el que se sustenta la inmensa mayoría de las políticas de defensa de la competencia, parte de la base de la existencia en un sector determinado de una sola organización empresarial que controlaría la producción de un determinado bien o servicio, imponiendo de esta forma condiciones abusivas a los clientes o precios de monopolio claramente explotadores del consumidor y de la idea antes reiterada de una 
situación ideal de competencia. De aquí se derivan buena parte de las intervenciones en los precios, regulaciones comerciales (apertura de establecimientos, horarios de apertura...), prohibición o incentivo de fusiones empresariales, entre otras muchas medidas. De esta forma, el Estado sería el encargado de proteger al mercado y a los ciudadanos de sus propias decisiones de consumo, interviniendo de forma coercitiva en las empresas que se aparten de esa situación ideal.

\section{Argumentos de tipo ético-filosófico}

La otra gran fuente de argumentos a favor de la existencia de políticas públicas es la ausencia de equidad en los resultados de los procesos de mercado. Se parte de la idea de que los mercados están compuestos por individuos u organizaciones con poder de negociación y organización muy distintos y esto conduce a situaciones de desigualdad manifiesta en las condiciones económicas de los miembros integrantes de la sociedad, tanto en el interior de los países como en las relaciones entre ellos. Se reputa esta desigualdad como injusta moralmente y se reclama la actuación correctora del Estado para corregir tal injusticia social. Este tipo de justificaciones presuponen la posibilidad de realizar comparaciones interpersonales de utilidad, al establecerse de forma supuestamente objetiva cuáles son las utilidades percibidas por cada individuo en incrementos o decrementos en su renta ${ }^{13}$. Medidas de política como los impuestos progresivos sobre la renta, restricciones al comercio internacional, financiación pública de la sanidad, educación pública igualadora, ayudas públicas tanto materiales como legales a favor de determinados colectivos percibidos como marginados (discriminación positiva) que consumen la mayor parte de

${ }^{13}$ Un repaso y una crítica a estas justificaciones, englobadas en la llamada economía del bienestar, pueden verse en Rothbard (1956). 
los presupuestos estatales, son ejemplos de políticas públicas inspiradas por motivos éticos o morales. Se trata siempre en estos casos de que el Estado actúe para proteger al débil frente al fuerte o al pequeño contra al grande y poderoso. En muchas ocasiones, los argumentos expuestos en el apartado a) de este epígrafe están inspirados, en última instancia, en una visión justa y equitativa de lo que deben ser los procesos de mercado, y, por tanto, la mayoría de los argumentos científicos no dejan de ser sino intentos de dar un barniz teórico a valores morales previamente existentes.

\section{ANÁLISIS CATALÁCTICO \\ DE LA JUSTIFICACIÓN DE LA INTERVENCIÓN: ANÁLISIS DEL CASO DE LAS POLÍTICAS DE DEFENSA DE LA COMPETENCIA}

Los argumentos antes expuestos son aceptados por la mayoría de las escuelas económicas dominantes en los medios académicos contemporáneos, si bien con diferencias entre ellas. Los keynesianos las adoptan como ciertas para justificar de este modo sus políticas intervencionistas, lo mismo que los neoclásicos, que se consideran a sí mismos más liberales porque en vez de reclamar la intervención directa del Estado como los discípulos de Keynes, reclaman mercados tutelados por el Estado para resolver esta problemática ${ }^{14}$. Sólo la escuela austriaca cuestiona la validez de los argumentos justificatorios de la intervención gubernamental negando la validez de la funda-

14 Sería el caso, por ejemplo, de los mercados de polución. El Estado limita la polución a una cantidad dada de toxinas y después vende en una subasta el derecho a contaminar. Conviene recordar que el garante último de que no se sobrepase la cantidad «legítima» de polución es el Estado, el mismo que sanciona a quien no respete los límites fijados «científicamente» por expertos o grupos de presión interesados en tales límites. 
mentación económica de los mismos ${ }^{15}$. La escuela austriaca de economía parte de una estricta neutralidad axiológica, conviene recordarlo, y no cuestiona, por tanto, la necesidad del Estado ni toma una postura como tal escuela sobre el grado de intervención que debe adoptar el Estado en la economía, al considerarlo una cuestión ajena al ámbito de la cataláctica o estudio de los fenómenos que acaecen en el mercado. La escuela austriaca se limita a exponer las consecuencias de tal intervención (Mises, 2002) y a analizar la validez praxeológica de los argumentos expuestos en su defensa, que, como veremos, es prácticamente nula, dejando libres a los individuos para que después decidan políticamente por los motivos que crean pertinentes.

En este epígrafe queremos abordar las críticas praxeológicas de la escuela austriaca a tales argumentos, centrándonos especialmente en las críticas que se realizan al funcionamiento del mercado, esto es, en aquellos argumentos que pretenden salvar al mercado de sí mismo imponiéndole restricciones, como es el caso de las políticas de defensa de la competencia, pues los otros argumentos no se refieren propiamente al funcionamiento de los mercados, sino que son fallos del Estado propiamente dicho. En efecto, tanto lo que se refiere a las externalidades como a los bienes públicos, son, en ambos casos, fallos del Estado, como bien apuntan los economistas austriacos. Los efectos externos sólo se dan en ámbitos socializados, esto es, sujetos a la tutela del Estado, o en ámbitos en los que no existen derechos de propiedad. De hecho, la consideración de una externalidad como coste o beneficio no puede darse en ausencia de derechos de propiedad, pues ésta afecta en alguna medida a la propiedad de una o más personas y son éstas las que deciden si supo-

${ }^{15}$ Una crítica general de los principios que rigen la economía del bienestar (eficiencia, comparación interpersonal de utilidades...) y, por tanto, justifican la intervención estatal, puede verse en Rothbard (1956). 
ne un bien o un mal ${ }^{16}$. El sonido de las campanas, por ejemplo, será un coste o un beneficio según el afectado, del mismo modo que no hay una definición objetiva de lo que es un mal olor o de si la música del vecino es una obra maestra o un molesto ruido. Es al afectado en sus derechos de propiedad a quien corresponde determinar si es agredido o beneficiado por el bien externo y reclamar o negociar, por tanto, su cese, al menos en lo que a él le afecte. La externalidad negativa sólo se da en lugares públicos o comunes, como aguas de dominio público (ríos, mares, lagos, acuíferos subterráneos), no así en los manantiales privados, en el aire (también de dominio público) o en espacios públicos como calles, carreteras y otros ${ }^{17}$. El problema y la carga de la prueba recaen sobre quien se arroga la titularidad de esos ámbitos, que, como veremos, son ámbitos ajenos por completo al mercado, y es el Estado, por tanto, quien debe justificar por qué están más sucias las calles de las ciudades que las calles privadas de los grandes centros comerciales, o por qué el agua de balnearios y manantiales en donde se embotella con fines comerciales es más salubre que la de los ríos y embalses públicos, o por qué huelen peor los baños públicos que los de un establecimiento privado. En otros casos, como la defensa nacional, el argumento no sólo es falaz, sino cínico. La necesidad de defensa nacional nace de la existencia del Estado ${ }^{18}$ : esto es, si no existiesen Estados, las agresiones sólo podrían darse entre individuos o grupos primarios, y éstos no precisan de grandes organizaciones para defenderse ${ }^{19}$. Es la existencia de Estados

\footnotetext{
16 Un tratamiento desde la perspectiva austriaca de las externalidades puede verse en Benegas Lynch (1988), Block (1983), Huerta de Soto (1994) y Cordato (2004).

17 Este fenómeno que conduce a la sobreexplotación de los bienes públicos, también conocido como "tragedia de los comunes», es estudiado en Hardin (1989) y Anderson y Leal (1993).

18 Los ejércitos modernos son consecuencia directa de la existencia del Estado (Creveld, 1999).

19 En esto consiste el llamado "principio de competencia política» de Bertrand de Jouvenel, que dice que cuando un Estado es capaz de explotar más intensiva-
} 
lo que hace que yo me preocupe por defender a individuos a los que no conozco, que viven a cientos de kilómetros de mi casa y cuya única relación conmigo es la de estar sujetos a la jurisdicción de un mismo Estado ${ }^{20}$. El argumento que se suele usar es que un grupo de individuos desorganizado no puede enfrentarse con éxito a la agresión ejercida por un Estado bien armado y organizado. Esto es cierto, pero, entonces, estamos justificando el Estado como necesidad de defendernos de una externalidad negativa (la posibilidad de invasión o agresión por las fuerzas organizadas de otro Estado) que es causada por la propia existencia de los Estados ${ }^{21}$. Es, pues, el causante del mal el que obliga a financiarlo para defendernos de sí mismo. Estamos ante un argumento, por tanto, cuando menos injusto y falaz.

El argumento de los bienes públicos tampoco puede ser sostenido desde una perspectiva económica, por varias razones. En primer lugar, por la indefinición del concepto que incluye infinidad de bienes, que comparten en mayor o menor medida los rasgos de los bienes públicos. El olor de un perfume no permite la exclusión de quienes lo huelen y un beneficiado más de la fragancia no altera el coste de obtención del perfume. Un calcetín, como nos recuerda el profesor Block, elimina malos olores corporales a los demás, beneficiándolos, y tampoco podemos excluir a los beneficiarios ni decir que un beneficiario más

mente a su pueblo por medio de la coacción, ya sea impositiva (impuestos) o personal (servicio militar), genera un potencial militar más grande que el de sus vecinos, que se ven al principio amenazados y/o agredidos hasta que imitan al pionero e incrementan la explotación de sus respectivos pueblos (Jouvenel, 1998).

20 También puedo verme en la obligación de atacar a gente que conozco, que vive cerca de mi casa y con la que tengo buen trato, sólo porque vive detrás de una barrera fronteriza distinta de la mía.

21 Esto abriría el debate sobre si es posible o no abolir el Estado en un solo país, pues el primero en hacerlo podría dejar a sus antiguos ciudadanos indefensos frente al temible potencial agresor de los demás Estados. Una estrategia de transición a una sociedad liberal que aborda algunos de estos problemas puede verse en Huerta de Soto (2002). 
altere el precio del calcetín, y así ocurre con muchos otros bienes de esta naturaleza que nadie pretende que sean suministrados públicamente ${ }^{22}$. En segundo lugar, el que un bien tenga características de bien público no implica que sea necesario forzar a la gente a financiarlo coactivamente, dado que éste puede ser financiado de forma privada o tal vez puede no ser deseable para muchos ciudadanos. En efecto, la totalidad de los bienes que hoy se consideran privativos del Estado (defensa, justicia, obras públicas...) pueden ser suministrados privadamente $\mathrm{y}$, de hecho, lo fueron en algún momento histórico. Tanto justicia (Benson, 2000) como defensa privadas (Hoppe, 2003); carreteras, puentes y calles, pueden ser, y de hecho son, en muchas ocasiones, privadas (Davies, 2002), e incluso el mítico faro, paradigma por excelencia de bien público, fue suministrado mediante suscripciones a los navegantes en muchas localidades ${ }^{23}$ (Coase, 1994; Sechrest, 2003). En tercer lugar, no todo bien público es beneficioso ni agrada a todo el mundo, y por tanto es cuestionable que deba forzarse a toda la ciudadanía a financiarlo. Los gastos de defensa y el uso que se hace de ellos pueden ser cuestionables por muchas personas, pacifistas o no; la seguridad pública, si se usa para reprimir ideas políticas o para perseguir delitos sin víctimas como el tráfico de drogas o la prostitución, puede desagradar a muchas personas y transformarse incluso en un mal público; la construcción excesiva de calles y carreteras puede tener efectos indeseados, como facilitar el acceso a nosotros a gente con la que no queremos tratar (Hoppe, 2002) o destruir paisajes o espacios valiosos para otras actividades. En cuarto y último lugar, queda la cuestión

\footnotetext{
${ }^{22}$ Véase una enumeración de bienes de este tipo (el ejemplo del calcetín es suyo) y una completa bibliografía en Block (2002).

${ }^{23}$ Como curiosidad, hay que decir que fue precisamente la descalificación por parte de W. Buckley de las propuestas de Rothbard de privatizar los faros lo que separó definitivamente a éste de los círculos neoconservadores de la National Review, iniciando a partir de entonces una etapa nueva alejada de la derecha tradicional norteamericana.
} 
de si efectivamente los bienes públicos cumplen con los rasgos de la no exclusión y de que no se incrementa el coste por un usuario más. Esto no es del todo cierto. En lo que respecta a la no exclusión, es cierto que determinados bienes, como la defensa nacional, la seguridad o una banda de música tocando en la plaza pública, no pueden, una vez establecidos, privar a nadie de su disfrute. Ahora bien, la calidad del disfrute no es la misma para todos los usuarios, llegando a constituir bienes distintos según la situación del usuario. Por ejemplo, no todas las ciudades de España están igual de defendidas frente a un enemigo potencial. Todas los doctrinas militares establecen unos frentes y unos lugares a sacrificar frente a ataques enemigos, de la misma forma que se establecen objetivos de defensa estratégicos que privilegian a unas ciudades (normalmente, las sedes del gobierno) y perjudican a otras. Lo mismo se puede decir respecto a la seguridad, pues también aquí hay barrios más protegidos (normalmente, donde residen los políticos, que cuentan con escoltas y el derecho a portar armas) y otros marginados; hay ciudades bien comunicadas por carretera y otras que no lo están, etc. En lo que respecta al concierto de música, se sabe que no se escucha por igual en toda la plaza y normalmente un buen puesto requiere esfuerzo, sea de tiempo o de dinero, para poder disfrutarlo en las mejores condiciones ${ }^{24}$. Así, no todos disfrutan por igual del bien público, y, por tanto, podemos decir que, si bien existen bienes públicos, éstos no son del mismo tipo para todos los ciudadanos, pudiéndose afirmar que se trata de bienes distintos (Rothbard, 1993). En lo que respecta a la afirmación de que un usuario más no incrementa el coste, podemos decir que es otra media verdad. En la producción de bienes públicos, como en muchos otros bienes, se dan fenómenos

\footnotetext{
${ }^{24}$ Como se puede comprobar en el caso de las bodas reales, en las que se llegan a subastar espacios para disfrutar de una buena visión de algo que en teoría debería de ser un bien público.
} 
de escala y umbral, e incorporar un usuario más puede tener un elevado coste marginal que desmiente la suposición de base. Por ejemplo, incorporar una determinada zona a la recepción de programas de televisión necesita de nuevos repetidores; defender un territorio pequeño, como una isla o un enclave ${ }^{25}$, puede dar lugar a cuantiosísimos gastos, lo mismo que comunicar por carretera a un pueblo aislado.

Sin embargo, las justificaciones de la intervención estatal menos consistentes son aquellas que pretenden salvar al mercado de sí mismo, esto es, aquellas que presumen que permitir acuerdos libres entre las partes conllevaría graves problemas de abusos y restricciones en las libertades de la ciudadanía, haciéndose, por tanto, necesaria la restricción de la libertad económica precisamente para salvaguardar tal libertad, y que son denominados fallos de mercado. Todas ellas parten de un punto común, la idea neoclásica de monopolio, situación apartada del esquema ideal de competencia perfecta ${ }^{26}$ al que antes

${ }^{25}$ El caso de las islas españolas del estrecho de Gibraltar podría ser un buen ejemplo de lo dicho. Los gastos necesarios para defender a sus poquísimos habitantes consumen buena parte del presupuesto de defensa español. Los consumidores marginales sí cuestan, y mucho.

26 Este modelo ideal presupone además información perfecta, esto es, que todos los individuos poseen igual información, situación imposible praxeológicamente de entrada porque desconoce el factor tiempo, es decir, por el mero hecho de vivir aprendemos cosas que los individuos que vienen después aún desconocen. Este supuesto, que imposibilitaría cualquier división del trabajo, justifica, sin embargo, gran número de intervenciones del Estado. Se parte de la base de que si existe información asimétrica, una de las partes puede estafar o engañar a la otra. Esto podría ser cierto, pero se olvida que el mercado desarrolló a lo largo de su historia un gran número de instituciones encaminadas a dificultar tal abuso. Desde la propia existencia de la competencia, el principio del caveat emptor, pasando por todas las organizaciones privadas certificadoras de calidad (véase al respecto Blundell y Robinson, 2000); lo mismo sucede con el supuesto de la capacidad de predicción perfecta de las consecuencias de nuestras acciones o de las repercusiones de eventos futuros sobre nuestros actos. Sobre estos aspectos es interesante consultar la obra del Nobel Herbert Simon, quien, influido por Hayek, realizó una durísima crítica de los supuestos de comportamiento del neoclásico Homo Economicus (Simon, 1958). Desde un punto de vista austriaco, ver al respecto el excelente trabajo de Jorg Guido Hülsmann (Hülsmann, 2000). 
aludíamos y causada por la codicia de algún poderoso conglomerado empresarial que buscaría monopolizar un área del mercado para, una vez capturada ésta, poder imponer abusivos precios de monopolio que castigarían a pobres ciudadanos desprotegidos a los que el Estado tendría que salvaguardar por la vía de forzar al codicioso monopolista a aceptar la competencia de otras empresas y, en caso de persistir en tan abusiva práctica, a fragmentar o dividir tan perniciosa organización.

Todo parte de la idea, muy antigua en el tiempo ${ }^{27}$, de la empresa monopolista como la organización que pretende hacerse gracias a malas artes ${ }^{28}$ con el dominio de la producción en

27 A diferencia de las ideas de externalidad, de bien público y de competencia perfecta, que tienen su origen en el pensamiento económico del siglo XX, la idea de abusos en el mercado y de la necesidad de una intervención correctora por parte de la autoridad es tan vieja como la propia actividad mercantil, como se nos recuerda en una célebre compilación de ensayos al respecto, dirigida por Karl Polanyi. (Polanyi, 1976). Una crítica a las ideas de Polanyi puede encontrarse en Rothbard (2004).

28 Estas malas artes, que buscan en última instancia hacerse con el mercado para aplicar precios de monopolio, consisten en el abuso de posición dominante (ya sea cobrando precios abusivos derivados del monopolio, ya sea discriminando en los precios cargados a los clientes), en la colusión de precios y en el precio predatorio, o cargar precios por debajo del coste para arruinar a la competencia, hacerse con el mercado y luego resarcirse cobrando precios de monopolio. Véase una crítica detallada a estos postulados en $\operatorname{Kirzner}(1989,1999)$, DiLorenzo (1992), Anderson (2003) y Armentano (1999). En resumen, en una economía de mercado libre es imposible sostener durante mucho tiempo estas prácticas, pues el exceso de beneficios que obtendrían las empresas monopolistas atraería nuevos capitales al sector, disminuyendo de nuevo la tasa de beneficio de la empresa monopolista. Sólo la regulación estatal puede mantener a largo plazo a una industria en situación de dominio monopolista. Pero conviene recordar que aun en el hipotético caso de que estas prácticas se diesen y se mantuviesen en el tiempo, éstas no constituirían nada inmoral ni, por tanto, estaría legítimamente justificada la intervención correctora estatal. Los propietarios de un bien o recurso cualquiera tienen el derecho de venderlo al precio que ellos estimen pertinente, ya sea muy por debajo o muy por encima del inexistente precio justo o común, lo mismo que llegar a acuerdos libres con otros vendedores o productores para pactar precios. Es su propiedad y pueden hacer con ella lo que deseen, y corresponde al consumidor libremente aceptar o no tales condiciones. Entre varios economistas austriacos se planteó un debate iniciado por Israel Kirzner sobre si en algún caso con- 
un determinado sector para a continuación imponer al consumidor necesitado de esos productos un precio muy superior al que supuestamente se daría en ausencia de tal dominio monopolista, esto es, condiciones ideales de competencia perfecta, y, por tanto, explotar y esquilmar al pobre consumidor. De aquí se derivaría la necesidad de la intervención del Estado para corregir tales abusos, creándose, incluso, para tal fin instituciones especiales como los tribunales de defensa de la competencia.

Aparte de que, como vimos en la nota anterior, es prácticamente imposible que un monopolio se derive de tan malas artes, la crítica realizada desde la escuela austriaca a esta justificación de la intervención pasa por cuestionar el concepto de monopolio habitualmente usado. Para los austriacos, hablamos de monopolio cuando existen barreras legales de entrada a un determinado sector económico ${ }^{29}$. El concepto de monopolio

creto el libre mercado derivaba en un monopolio que dañase al consumidor (recordemos que Mises propugnaba que el libre mercado favorecía siempre al consumidor) y por tanto podía justificarse algún tipo de corrección en este caso hipotético. Esto no es en ningún modo así porque no hay ninguna norma que diga que el productor tenga que estar al servicio del consumidor ni beneficiarlo, pues esto sólo el consumidor lo puede saber. El monopolio obtenido honradamente en el mercado debe poder permitir a su propietario cargar el precio que estime oportuno, pues eso forma parte de sus derechos de propiedad, que no debe poder ser limitada por ninguna suerte de supuesto interés público o general.

29 No se puede hablar de precio de monopolio en condiciones de mercado libre porque o bien todos los precios son de monopolio, al ser cada bien y su circunstancia únicos (cada trabajador es único, la proximidad de una tienda puede hacerla de facto monopolista para mí por su distancia y por su trato, la cocina de un restaurante determinado es única...), o bien porque ninguno lo es, al tener todos los bienes o servicios la posibilidad de competencia por parte de todos los demás bienes, y, por tanto, su capacidad de imponer precios de monopolio estará limitada por esta competencia — si una empresa monopoliza la electricidad, por ejemplo, y sube el precio demasiado a mi entender, tendré que renunciar, para poder pagar la electricidad, a zapatos, a bocadillos o a cualquier otra cosa que yo prefiera; de hecho, antes se vivía sin ella y hoy muchas personas viven en el mundo sin ella, e incluso, para algunos primitivistas radicales como John Zerzan y su Futuro Primitivo (Zerzan, 2001), puede ser incluso una bendición vivir sin ella. Lo mismo puede predicarse de cualquier otro bien-. Véase Rothbard (1993) y Block (1977). 
o de oligopolio austriaco no depende del número o del porcentaje de mercado que acapare una o varias empresas, sino de que exista o no libre acceso a tal sector, de tal forma que si en un determinado sector se da de facto la existencia de una sola empresa, no cabe más que afirmar que tal es la situación que más satisface a los consumidores, siendo no una prueba de abuso sino de eficaz y satisfactorio desempeño. El caso de Microsoft sería un ejemplo claro de lo antedicho ${ }^{30}$. Las empresas de software como Microsoft operan con externalidades de red, esto es, que cuanta más gente haga uso de un producto o servicio, más ventajoso es para el usuario, y, por tanto, los usuarios se verán favorecidos por la existencia de una única empresa que garantice la compatibilidad a nivel mundial de software y accesorios (por ejemplo, nuestros archivos pueden ser leídos por cualquier otro computador del mundo), abaratando al mismo tiempo los precios de los mismos al permitirse la producción a gran escala. En este caso, el monopolio es decidido por el consumidor porque claramente le beneficia, siendo necesario, como en el caso español, el apoyo explícito de las Administraciones públicas ${ }^{31}$, en nombre de una supuesta necesidad de libre competencia, para imponer programas alternativos como Linux, que podrían perfectamente aparecer sin apoyo institucional en el caso de ser deficientes o realmente abusivas las condiciones impuestas por Microsoft a sus usuarios ${ }^{32}$. Otro

30 Un ejemplo del tratamiento del caso de Microsoft desde una perspectiva no austriaca puede verse en Cuervo y Sandulli (2003).

31 Es el caso de algunas Administraciones públicas españolas, que parecen haberse embarcado en una carrera por imponer institucionalmente el llamado software libre, para así romper el «monopolio» de Microsoft.

32 Se acusa a Microsoft de que su software no acepta software de otras casas, requiriéndose por vía legal el código fuente para poder adaptar otros productos. Este requerimiento vulnera por completo los derechos de propiedad de Microsoft y, por ende, la libre competencia. Mi automóvil no acepta repuesto de otras marcas, lo mismo que mi maquinilla de afeitar no acepta cuchillas de otras marcas, y nadie ve esto como un abuso monopolista. Yo cuando compro estos productos lo sé y acepto estas condiciones porque entiendo que el producto me compensa. De 
ejemplo sería el de las fusiones de los canales de televisión digitales sujetos a la autorización gubernamental. Muchos economistas supuestamente defensores del libre mercado reclaman la intervención gubernamental para que fuerce la existencia de más de una cadena digital para garantizar de esta forma la competencia, sin darse cuenta de que, en ocasiones como ésta, el mercado sólo tiene capacidad de absorber una sola plataforma que combine los contenidos de las dos plataformas existentes. El problema es de escala o de tamaño del mercado. De la misma forma que entre Vigo y Santiago, por cuestiones de población y renta, sólo es rentable una autopista de peaje, siendo absurdo obligar a construir otra para que exista competencia, sería absurdo obligar a que existan dos plataformas digitales cuando aparentemente sólo se demanda una, sin olvidar, por supuesto, el derecho de los propietarios a hacer con sus bienes lo que les plazca sin tener por qué pensar en un inexistente bienestar general que nadie es capaz de definir con precisión. Como deducimos de los casos anteriores, o de casos similares como el de la Standard Oil norteamericana ${ }^{33}$, en una situación de mercado libre, cuando una empresa es única en su sector, lo es por su capacidad de satisfacer las necesidades del consumidor, no porque abuse de su situación, siendo, por tanto, el Estado el único culpable de que existan monopolios abu$\operatorname{sivos}^{34}$. La teoría económica nos enseña que en caso de que un

la misma forma, cuando voy a un supermercado a comprar una marca blanca no protesto porque el propietario del supermercado no facilite el acceso a marcas blancas de la competencia a sus estantes.

33 DiLorenzo demuestra, en el artículo arriba referenciado, que en la inmensa mayoría - por no decir en la totalidad- de los casos que él estudió, las empresas sujetas a las sanciones de las leyes antimonopolio no cumplían el supuesto de abusos en el precio, sino todo lo contrario, eran empresas que abarataron sustancialmente el precio de los productos que fabricaban, viéndose atacadas judicialmente por competidores resentidos.

34 En muchos casos, el Estado actúa para proteger los espurios intereses de las empresas ya existentes en el sector, pues no hay peor enemigo, por ejemplo, de una nueva superficie que la ya existente; eso sí, se hace en nombre del pequeño 
sector económico, en situación de mercado libre, obtenga beneficios muy superiores a los del conjunto de la industria, se producirán desplazamientos de capitales desde las industrias menos rentables a las más rentables, rompiéndose de esta forma, de ser reclamado por los consumidores, el monopolio u oligopolio. Sólo el Estado puede impedir tal movimiento de capitales prohibiendo la entrada en el sector para favorecer a las empresas ya existentes o bien regulando el número o los requisitos de acceso a tal industria, como en el caso de las plataformas digitales, en el que es el Estado quien concede las licencias para tales industrias, restringiendo el acceso a cadenas extranjeras que pudieran de hecho romper el duopolio.

La teoría neoclásica del monopolio y del oligopolio está, además, sujeta a muchas otras críticas. En primer lugar, los defensores de la intervención estatal no definen bien el ámbito al que se correspondería el monopolio. No se especifica en la teoría cuál es el territorio mínimo en el que se da el monopolio ni cuál debe ser. Debemos recordar que el ámbito geográfico de un Estado es una dimensión política, que no puede ni debe confundirse con la adecuada dimensión económica ${ }^{35}$. Hay Estados soberanos, como Mónaco o Andorra, del tamaño de pequeños municipios españoles; unidades subestatales, como California, con decenas de millones de habitantes y con un potencial económico que las situaría por sí solas entre los siete grandes, o barrios de grandes ciudades con más habitan-

comercio agredido y para evitar abusos. Ver algunos ejemplos en Boudreaux y DiLorenzo (1993).

35 Una crítica del Estado-nación como unidad económica puede verse en Jacobs (1996). La autora defiende, en medio de ideas mercantilistas, que las verdaderas unidades de análisis económico deben ser las ciudades y sus áreas de influencia. Hayek, por su parte, relativiza la extendida idea de que la nación es una unidad de análisis económico correcta (Hayek, 1937). Un correcto análisis económico requerirá, por tanto, pensar, bien en una imaginaria nación aislada por completo del exterior, bien en el mundo en su totalidad, lo que es más realista. Los indicadores agregados de contabilidad nacional aíslan artificialmente a una nación de su entorno y son causantes de muchos errores en el análisis económico. 
tes que países europeos como Irlanda. Lo que intentamos clarificar con esto es que la existencia de una única empresa en un Estado determinado no implica monopolio per se, de la misma forma que de la existencia de una única mercería en un pueblo pequeño ningún economista denuncia la existencia de un monopolio; simplemente, en tal pueblo el mercado de lanas y artículos de costura sólo puede justificar la existencia de una sola tienda de tales características. Por tanto, en Estados de pequeño tamaño puede ser perfectamente normal la existencia de una sola empresa en un determinado sector sin que pueda en justicia ser llamada monopolio, pues económicamente hablando no hay diferencia entre un Estado poco poblado y un pueblo del mismo número de habitantes. Los criterios políticos y geográficos son, pues, de poca utilidad a la hora de determinar cuándo hablamos de un monopolio territorial, al no determinarse cuál es la dimensión territorial que hay que someter al dominio del monopolio para que pueda determinarse con objetividad su existencia. Tampoco los criterios de población nos sirven. No podemos decir tampoco que un monopolio o un oligopolio existen, de acuerdo con la teoría económica, cuando, por ejemplo, hay una sola compañía de telefonía por cable para un millón de habitantes, pues todo dependerá del potencial de riqueza y, por tanto, de la densidad telefónica del lugar. En Galicia, con casi tres millones de habitantes, podríamos sostener tres empresas de estas características. En Nigeria, con cien millones de habitantes, es dudoso que se pueda sostener más de una compañía, pues la capacidad adquisitiva del país puede no demandar más que una o ninguna. ¿Cuál es, pues, el umbral a partir del cual podemos definir el monopolio en términos de población? Además, el monopolio, el concepto neoclásico de monopolio, peca de imprecisión al no determinar el lapso temporal preciso para ser considerado tal. Una de las grandes virtudes de la escuela austriaca es la de incorporar el factor temporal a sus análisis, esto es, no considerar los ajus- 
tes económicos como automáticos e inmediatos, sino como eventos que requieren tiempo y empresarios para llevarlos a cabo. El factor tiempo es importante para entender los fenómenos monopolistas y para demostrar la imprecisión de muchas de sus definiciones. Los fenómenos económicos no se producen al unísono. La primera empresa que se crea dentro de un sector es, por definición, monopolista durante un lapso de tiempo variable, precisamente por ser la primera en establecerse. Del mismo modo, una empresa que aparezca como competencia de otra ya instalada tardará algún tiempo en expandirse y se expandirá gradualmente, permaneciendo muchas localidades durante un tiempo sometidas de hecho a una situación monopolística. Es lo que ocurre, por ejemplo, en el mercado de los derivados petrolíferos. Las nuevas compañías que se establezcan, aun suponiendo la inexistencia de barreras legales de entrada, tardan tiempo en establecer su logística y se expanden gradualmente, permaneciendo en muchos sitios en la situación «monopolista» anterior, o incluso para siempre si a la nueva compañía no le apetece abastecer a un determinado mercado. De ahí las quejas de muchos defensores de la libre competencia y las demandas de intervención de dicho sector para garantizar la libre competencia. Pero lo que en ningún caso se precisa es cuál debe ser el lapso temporal necesario para que una empresa merezca el apelativo denigrante de monopolista. También es habitual decidir la intervención de un sector cuando una empresa alcanza un determinado porcentaje de mercado, como es el caso de las grandes superficies comerciales, que no pueden controlar - sin riesgo de ser sancionadas- más de un porcentaje determinado de su teórico mercado en un territorio determinado. Dejando aparte la injusticia de castigar a quien satisface mejor al consumidor hasta el punto de conseguir tal grado de respaldo en el mercado, cabe considerar por qué se escoge una cifra determinada, digamos el $70 \%$ del mercado, y no otra cualquiera. No hay criterio científico alguno distinto de 
la mera arbitrariedad que pueda justificar científicamente tal medida, aparte de que se pueden aplicar muchas de las objeciones anteriores. Cuando criterios extraídos de la geografía política se usan para definir conceptos catalácticos, lo único que se genera es confusión. De qué sirve definir a un determinado hipermercado como monopolista u oligopolista en Galicia, y multarlo u obligarlo a dividirse, cuando a 15 minutos del «monopolio», en Portugal, existe competencia sobrada, situada justo en la frontera y fuera de la jurisdicción definidora de lo que es o no es monopolio.

Con lo dicho anteriormente se trata de probar que la argumentación económica para justificar la intervención del Estado en la vida económica con la excusa de salvar al mercado de sí mismo ${ }^{36}$ no resiste un análisis riguroso. Se hace necesario, pues, recurrir a otro tipo de justificaciones que analizaremos a continuación.

\section{CRÍTICA DE LOS ARGUMENTOS ÉTICOS EN DEFENSA DE LA INTERVENCIÓN}

Además de los argumentos de orden económico que pretenden justificar la intervención estatal, los paradigmas económicos dominantes - y muy en especial el neoclásico- están plagados de justificaciones éticas de la intervención estatal disfrazadas de rigurosa ciencia. Es más, cuanto más se formaliza la

36 Hay, por supuesto, más intervenciones estatales justificadas sobre la base de las imperfecciones del mercado y la presupuesta estupidez o la falta de información, como lo son las regulaciones de consumo o las licencias profesionales, también, supuestamente, para garantizar desde el gobierno la calidad del servicio al pobre consumidor. Lo que no entiendo es cómo el mismo ciudadano estafado al comprar leche, pan o un automóvil, productos en los que tiene verdadero interés por informarse, pueda, en cambio, tener la capacidad de discernir entre sesudos programas políticos y económicos sin que lo engañen y sin necesidad de que lo protejan o tutelen, o participar en el diseño de complejos «presupuestos participativos» al estilo de Porto Alegre. 
ciencia económica, más deudora es de argumentaciones de corte ético o moral, lo que contrasta aún más con la verdadera ciencia económica libre de valores que caracteriza a la escuela austriaca. Conceptos valorativos como justicia social, o el equivalente preferido por los economistas de equidad en la distribución de la renta, crecimiento económico, desarrollo y subdesarrollo, bienes de mérito o precariedad laboral, o indicadores como el PIB per cápita o la tasa de IPC, entre otros muchos, son usados en el discurso económico como si existiese consenso sobre su significado y para justificar como científicamente rigurosa la intervención estatal sobre aspectos de la vida social y económica ${ }^{37}$. Así, se hará política para favorecer la equidad entre hombres y mujeres o se establecerán medidas para disminuir el crecimiento del IPC ${ }^{38}$ porque el mercado salvaje y completamente desregulado supuestamente no tendría en cuenta tales efectos dañinos para los ciudadanos, especialmente los más pobres. En definitiva, se justifica la intervención estatal en todos estos casos por motivos de ética social, esto es, porque es injusto que unos sean más ricos que otros o que unas regiones crezcan o sean más ricas que otras por culpa del mercado, o porque determinados ciudadanos no pueden acceder a algunos bienes a los que supuestamente se tiene derecho sin contraprestación previa por parte de uno (educación, vivienda, sanidad...), y se hace necesario por parte de los poderes públicos corregir tales y tan graves disfunciones. Esto habitualmente se categoriza de forma vaga como el derecho a una plena jus-

37 Sobre el proceso de transformación de ideas y valores, en concreto las ideas keynesianas, en «ciencia económica neutral», véase Brenner (1995).

38 Es curioso que cuando se actúa sobre el IPC se actúa sobre el indicador en sí, no sobre las causas, pagando las consecuencias normalmente sectores inocentes. En vez de vigilar la creación de dinero vía déficit o vía multiplicador bancario, se aborda el problema en muchas ocasiones poniendo precios máximos a las gasolinas o a los alquileres o a cualquier otro sector mal visto políticamente (las gasolinas tienen que ser baratas a la fuerza, mientras que si la leche es barata es una desgracia, ¡misterios de la política!). 
ticia social, palabra comodín que se aplica a toda situación social que no satisface ética o estéticamente a quien propugna la intervención ${ }^{39}$.

La crítica a estas justificaciones tiene que hacerse, por tanto, en el plano de la ética y los economistas austriacos elaboraron argumentos de corte ético y moral que deslegitiman por completo las pretendidas bases morales de los estatistas. La legitimidad de la justicia social como fuente de políticas públicas fue duramente cuestionada por Hayek, en varios de sus libros pero muy en especial en Derecho, legislación y libertad. En este libro Hayek demuestra la imposibilidad lógica de la existencia de algo llamado justicia social (Hayek, 1988; Jouvenel, 2000; Flew, 1996). La justicia o injusticia de una acción sólo puede ser predicada de una acción deliberada y consciente, no de eventos que escapen a la humana volición. Si yo le quito la comida a un chiquillo y me la como estoy cometiendo una injusticia, pero si ese chiquillo nace en una familia pobre (o feo ${ }^{40}$, débil, poco inteligente o simpático...) no es culpa de nadie en concreto, pues, primero, nadie decidió tal cosa deliberadamente, no pudiendo ser predicada tal situación como injusta social o individualmente, $\mathrm{y}$, segundo, nadie puede hacer un juicio externo, científico, sobre la indeseabilidad intrínseca de tal situación ${ }^{41}$. La supuesta injusticia de la desigualdad de opor-

39 Sobre la corrupción del lenguaje y el abuso del concepto «social», véase Hayek (1992).

40 Sobre la importancia social y económica de nacer feo o guapo y las extremas desigualdades generadas por este accidente, véase Etcoff (2000). Murray Rothbard, argumentando también contra las políticas igualitarias, hace una muy interesante comparación de las desigualdades entre altos y bajos (Rothbard, 2000).

${ }^{41}$ La pobreza puede en algunos casos ser consecuencia de formas de vida religiosas o ascéticas decididas deliberadamente, que valoren la pobreza como algo deseable. Lo mismo pasa con los otros factores de desigualdad: no se puede saber desde fuera del propio sujeto hasta qué punto se encuentra más o menos satisfecho con su situación, y, por tanto, ésta es percibida como injusta. La imposibilidad de hacer mediciones intersubjetivas de utilidad fue expuesta con mucha brillantez por Murray Rothbard (Rothbard, 1956). 
tunidades no se sostiene ${ }^{42}$. Primero, porque no es injusta, como acabamos de ver (Hazlitt, 1979), y segundo, porque es imposible garantizar la plena igualdad de oportunidades, pues tampoco existe tal cosa. El hijo de un biólogo partirá con ventaja si quiere ser a su vez biólogo y lo hará con desventaja si quiere ser actor o trapecista con respecto al hijo de un profesional de tales disciplinas. En una ciudad grande se parte con ventaja para muchas cosas, pero no para ser agricultor o cazador, si esas son las preferencias o aptitudes del chico. Todos nosotros, aun disfrutando de educación y recursos económicos, no podemos ser muchas cosas en las que potencialmente podríamos ser muy buenos por la imposibilidad de conocerlo todo. Quién sabe si este autor no pudo ser un excelente jugador de béisbol o un magnífico cantante de ópera china, ganando más dinero o siendo, quién sabe, más feliz. Por desgracia, en su Galicia natal no hay tradición de ninguna de estas cosas y ahora ya es tarde para comenzar. A estas desigualdades de oportunidades se suman las propias opciones vitales del individuo (casarse o no y con quién, estudiar o divertirse, trabajar más o menos...), que no se pueden igualar sin restringir libertades fundamentales del ser humano y que conllevan como consecuencia desigualdades en renta o estatus. Por tanto, las políticas redistributivas son, por naturaleza, injustas, pues se basan, primero, en un modelo normativo de lo que hay que igualar -normalmente, la renta monetaria o las propiedades-, sin darse cuenta de que, salvo que éstas hayan sido obtenidas por fraude o por fuerza, son fruto de desigualdades naturales previas en algún aspecto (Rothbard, 1995a). Nadie habla de distribuir la inteligencia (escuelas malas para los inteligentes y escuelas de elite para los menos dotados en este campo) o la belleza o

42 Una crítica sistemática de las doctrinas que defienden la redistribución como forma de alcanzar la «justicia social» puede encontrarse en Benegas Lynch (1997). 
el carácter emprendedor o las habilidades físicas de los futbolistas, por ejemplo, cuando son éstas, y su valoración por parte de los demás individuos, las que concluyen en una mayor renta. Además, tal redistribución de rentas puede ser tremendamente injusta para muchos individuos que, partiendo con desigualdad en algún ámbito de la vida, pueden querer usar esa renta para satisfacer tal desigualdad ${ }^{43}$. Una persona que nace en un medio cultural bajo puede querer adquirir rentas elevadas para poder comprar en el mercado la cultura que el hijo del catedrático universitario izquierdista disfruta en su casa desde que nació. El feo puede querer adquirir belleza a través de cirugía estética o ropas vistosas que compensen su desigualdad de partida en el mercado matrimonial, etc. Si forzamos la redistribución estamos condenando a esas personas a ser de por vida desiguales en esos ámbitos, lo que sí sería realmente injusto.

La moderna escuela austriaca, sobre todo a partir de autores anarcocapitalistas como Murray N. Rothbard y sus sucesores, va aún más allá y reclama la inmoralidad de cualquier tipo de intervención estatal en la regulación de la vida económica que no afecte a la protección de los legítimos derechos de propiedad. Estos autores no se centran en la mayor o menor disfuncionalidad de la intervención o en sus no intencionadas consecuencias, sino que se concentran en el carácter intrínsecamente coercitivo y denegador de la intervención estatal. La intervención estatal en la vida social implica siempre la negación bien del uso legítimo del propio cuerpo o de los bienes propiedad de uno. Rothbard (1970) distingue al respecto tres tipos de

${ }^{43}$ Recordemos que para los economistas austriacos, desde Menger, se entiende que el objeto de las rentas monetarias son los placeres físicos o psicológicos que se obtienen a través de los bienes que se adquieren con tales rentas. Queremos una casa grande por la necesidad psicológica de espacio, manjares por el placer que proporcionan y para evitar los rigores del hambre, vestido para evitar el dolor del frío y para satisfacer nuestra vanidad. 
intervención estatal: autista, que niega el uso de la propiedad o del cuerpo de uno sin obtener contraprestación el Estado (prohibición del suicidio o del consumo de drogas plantadas en nuestra propiedad...); binaria, aquella que impone una relación forzosa, monetaria o en especie entre el individuo y el Estado (servicio militar, impuestos, expropiaciones forzosas...); y triangular, aquella que impide que dos o más individuos establezcan libremente relaciones personales o comerciales entre sí y en los términos que ambas partes establezcan (prohibición de relaciones homosexuales entre adultos libres, prostitución, salarios mínimos, regulaciones de calidad...). En todos estos casos la coacción institucional agrede la vida y las libertades del individuo en lo que respecta a asuntos que sólo a él y a su propiedad conciernen, constituyendo de este modo una inmoralidad flagrante. Por ejemplo, las leyes de salario mínimo constituyen un claro ejemplo de intervención disfuncional económicamente, como bien demuestran los estudios de la escuela austriaca (Mises, 2002; Hazlitt, 1996). Pero además -y ésta es la principal aportación de académicos como Rothbardviolan la libertad de los agentes de pactar y de hacer de su vida lo que ellos deseen. Los argumentos éticos a favor de la intervención se vuelven entonces contra quienes los propugnan.

Otro ejemplo de coacción institucional sería el de establecer objetivos de política económica aparentemente benignos y justificados éticamente, como son los de promover a través de la planificación estatal el crecimiento del PIB o el desarrollo económico. Estos objetivos, en realidad, son de corte ideológico moral, pero, vendidos a la opinión pública como pura racionalidad económica, no dejan de ser valoraciones propias del gobernante $^{44}$. En efecto, las valoraciones de los individuos se corresponden con los gustos y preferencias de cada uno, no

${ }_{44} \mathrm{Al}$ respecto, resulta muy interesante consultar la desmitificación que hace Rothbard de este tipo de semántica económica (Rothbard, 1995b). 
pudiendo existir ninguna valoración «social» por encima de las valoraciones individuales (Rothbard, 1956). Todas las personas escogen de acuerdo con sus valores e inclinaciones una determinada combinación de trabajo y ocio, y no es, por tanto, moralmente legítimo por parte del Estado imponer a un individuo valores que le puedan ser ajenos o que violen su conciencia. Hay individuos que pueden preferir legítimamente, y asumiendo las consecuencias de tal elección, vivir trabajando poco y en un entorno rural y poco desarrollado, mientras otros prefieren también legítimamente ganar mucho dinero trabajando mucho y viviendo en entornos más apropiados a tal fin. El desarrollo no se puede ${ }^{45}$ forzar por el Estado, aunque muchas personas así lo prefieran, mediante políticas, pues sólo conducirá a subordinar las preferencias individuales para satisfacer los -en muchas ocasiones- espurios intereses de los gobernantes (además de que es muy probable que tal planificación central no consiga sus objetivos sino que empeore aún más la situación, como se pudo comprobar con la planificación en los países socialistas).

\section{CONCLUSIÓN}

En este artículo tratamos de demostrar la insolvencia de las justificaciones científicas o éticas de la existencia del Estado como elemento regulador de la vida social. Curiosamente, los mejores y más brillantes argumentos a favor de la existencia del Estado son los que se olvidan de la ciencia y de la ética y recurren en cambio a elementos aparentemente menos racionales

45 En efecto, el Estado no tiene capacidad, a través de su intervención activa, de conseguir el desarrollo económico (entendido, claro está, como mejora en el bienestar material de los ciudadanos de un país). Sólo los individuos a través de instituciones como el mercado o la propiedad privada, entre otras, pueden conseguir tal objetivo (Bauer, 1988). 
como la tradición y el hábito, además del crédito mágico y misterioso en el gobernante, como bien reconocen Rothbard (Rothbard, 1978) y Jouvenel (Jouvenel, 1998). La fuente principal de legitimación de la existencia del Estado sigue siendo su carácter misterioso y casi sagrado (véase, si no, el misterio y secretismo de los grandes bancos centrales), heredado de los tiempos del derecho divino de los reyes y al que bajo ningún concepto renuncian los Estados actuales y su continuidad y duración en el tiempo como tales Estados (la principal excusa para evitar movimientos secesionistas pacíficos es que rompe con una larga tradición histórica de estabilidad), y en los costes que tal transición acarrearía ${ }^{46}$. El carácter mágico, taumatúrgico, del Estado hace que éste aparezca como omnipotente, capaz de resolver todos los problemas del individuo y, como el viejo monarca, se somete a todo tipo de peticiones por parte de los administrados, que ven en él, gracias a la labor legitimadora de los intelectuales de la corte, un ente benigno dispensador de favores y gracias. Además, el Estado se configura según esta visión como el único garante de la paz social, como algo inevitable (Holcombe, 2004). De ahí que autores como Hobbes, uno de los mejores teóricos del Estado de todos los tiempos, incidan en este aspecto a la hora de defender la existencia del Estado, como un ser maligno pero necesario para imponer la paz social, dejando a un lado visiones contractua-

46 Una de las principales deficiencias del pensamiento libertario reside en su falta de una teoría política de la transición a una sociedad sin Estado y una evaluación teórica de sus costes. Cuestiones como si un Estado en concreto puede disolverse él solo o si todos los Estados deben disolverse a la vez, o de si es posible para un movimiento político libertario que cuente sólo con una parte - aunque mayoritaria- de los votos, disolver las instituciones políticas y abolir toda posibilidad de reversión a la situación anterior, son insuficientemente tratadas por los pensadores libertarios. Un actor hayekiano como Kukathas apunta algo de esto (Kukathas, 2003). Rothbard escribió un libro sobre este tema que por desgracia permanece inédito, aunque en Internet (agradezco a Roberto Suárez la referencia) se puede encontrar un resumen (Rothbard, 1977). Sin embargo, este tema es abordado parcialmente en Huerta de Soto (2002) y de nuevo en Rothbard (1992). 
listas más benignas hacia el Estado pero también menos realistas (Block y DiLorenzo, 2000). Por su parte, la legitimación temporal del Estado, sobre todo gracias a la identificación histórica de los Estados actuales con dinastías históricas de reyes o aristocracias, es una legitimación como la anterior, basada en aspectos aparentemente irracionales como es el mero discurrir del tiempo, pero que, sin embargo, como nos recuerda Hoppe (Hoppe, 2001) al referirse a la racionalidad de las monarquías, introduce elementos de estabilidad y de perspectiva temporal de los gobernantes, algo que la racionalidad «científica» no es capaz de ofrecer. Observemos la forma que tienen los Estados actuales, que no es para nada la más racional técnica o económicamente (Friedman, 1977; Buchanan, 2003). Incluyen espacios heterogéneos muy difíciles de comunicar y que están unidos por meros avatares históricos. Un Estado construido de acuerdo con principios racionales probablemente tendría otras formas supuestamente más racionales, pero estaría sometido siempre al propio dictamen de la razón económica o técnica, de tal forma que cuando las condiciones económicas o técnicas cambiasen tendría también que hacerlo la forma del Estado, dificultando, por tanto, una adecuada perspectiva temporal en los gobernantes, que no sabrían si el gobierno seguiría siendo suyo al cabo de un tiempo, no estando, por tanto, interesados en su conservación y prosperidad a largo plazo $^{47}$. Otro tipo de justificación interesante, pero tampoco científica en el sentido antes analizado, sería la que ve al Estado como un ente que, si bien nace de la violencia y la predación (Tilly, 1985; Rustow, 1980), es, en su forma moderna de Estado benefactor, el

47 De la misma forma, el monarca, al considerarse él y su familia como propietarios del Estado, tendrá interés en conservar la prosperidad de sus gobernados a largo plazo pues él también se verá beneficiado a largo plazo, mientras que la perspectiva temporal del gobernante democrático es mucho más limitada, como sabemos por los estudios de la Public Choice, y buscará obtener beneficio a corto plazo sin tener en cuenta el porvenir de sus gobernados. 
resultado de la evolución histórica de la misma forma que otros órdenes espontáneos (Ikeda, 1997).

Con lo anterior no queremos decir que la existencia del Estado esté justificada. Precisamente por ello no se estudian en este trabajo las críticas a la intervención estatal procedentes de la escuela neoclásica, conocida como escuela de la Elección Pública, porque este paradigma no aborda el problema de la raíz última de la existencia de políticas públicas, al dedicarse sólo a analizar los fallos del sector público, comparándolos a continuación con los del sector privado sin cuestionarlo nunca en su origen (Wolf, 1995; Stanbury y Thompson, 1995). Sólo que los argumentos supuestamente científicos y filosóficos que apoyan su existencia no se se pueden justificar teniendo que recurrir, como en la antigüedad, a temores derivados de la ausencia de Estado o a misteriosos conjuros, eso sí, adaptados a la retórica de hoy, de los modernos chamanes que rigen nuestras finanzas ${ }^{48}$, que son y no pueden ser otros los únicos asideros a que pueden recurrir los defensores del Leviatán. El problema que se les plantea es que su propio discurso ataca con dureza a este tipo de justificaciones, quizá porque ahí no se pueden encontrar con facilidad argumentos legitimadores de muchas de las políticas que hoy se llevan a cabo y, por lo tanto, restringen su capacidad de actuación ${ }^{49}$. Y, en definitiva, cuando se ven atacados con argumentos praxeológicamente rigurosos, tienen que refugiarse en argumentos que previamente ellos mismos habían denostado ${ }^{50}$.

48 Rothbard se refiere en su libro al aura de misterio que rodea a los modernos banqueros centrales y a su lenguaje críptico (Rothbard, 1994).

49 Sobre el carácter limitado del derecho divino de los reyes, es muy interesante Kern (1955)

50 Recuérdese cómo se aprovechó el caos provocado por las tropas norteamericanas en su invasión de Irak para recordarle al mundo el caos que se daría en ausencia del Estado, de la misma forma que algunos gobernantes de pueblos de la antigüedad permitían varios días de anarquía a la muerte de un rey para que el pueblo añorase la llegada de nuevo del gobierno. El problema es que en ninguno de estos casos se permitía la creación de instituciones surgidas de la sociedad civil encargadas de mantener el orden. 


\section{BIBLIOGRAFÍA}

ANDERSON, D.R. y LeAL, T.L. (1993), Ecología de mercado, Madrid, Unión Editorial.

Anderson, W.L. (2003), «Pounding Square Pegs into Round Holes: Another Look at the Neoclassical Theory of Predatory Pricing», en Quartely Journal of Austrian Economics, vol. 6, n. ${ }^{\circ}$ 1, Spring, pp. 23-40.

Aranzadi del Cerro, J. (1999), Liberalismo contra liberalismo. Análisis teórico de las obras de Ludwig von Mises y Gary Becker, Madrid, Unión Editorial.

Armentano, D.T. (1999), Antitrust. The Case for Repeal, Auburn, Ludwig von Mises Institute.

Bauer, P.T. (1988), Crítica de la teoría del desarrollo, Barcelona, Orbis.

BeNEGas LynCH, A. (1988), «Bienes públicos, externalidades y los free-riders : el argumento reconsiderado», en Estudios Públicos, n. ${ }^{\circ}$ 71, invierno.

- (1997), «Socialismo de mercado», en Libertas, n. ${ }^{\circ}$ 127, Año XIV, octubre.

Benson, B.L. (2000), Justicia sin Estado, Madrid, Unión Editorial.

BLOCK, W. (1977), «Austrian Monopoly Theory. A Critique», en Journal of Libertarian Studies, vol. 1, n. ${ }^{\circ}$ 4, pp. 271-279.

- (1983), «Public Goods and Externalities: The Case of Roads», en Journal of Libertarian Studies, vol. VII, n. ${ }^{\circ} 1$, Spring, pp. 1-34

- (1989), «The Justification for Taxation in the Public Finance Literature: An Unorthodox View», en Economia delle scelte pubbliche, vol. 3, pp. 141-158.

- (1993), «Public Finance Texts Cannot Justify Government Taxation: A Critique», en Canadian Public Administration, vol. 36, n. ${ }^{\circ}$, pp. 225-262.

Block, W. y DiLorenzo, T.J. (2000), «Is voluntary Government Possible? A Critique of Constitutional Economics», en 
Journal of Institutional and Theoretical Economics, vol. 156, n. ${ }^{\circ} 4$, December, pp. 567-582.

- (2002), «All Government is Excessive: A Rejoinder to Dwight Lee's "In Defense of Excessive Government" », en Journal of Libertarian Studies, vol. 16, n. ${ }^{\circ}$ 3, Summer, pp. 35-82.

Blundell, C. y Robinson, J. (2000), «Regulación sin el Estado», en Libertas, n. ${ }^{\circ} 20$.

BoetTKe, P. y LeEson, P. (2002), «The Austrian School of Economics», en Jeff Biddle y Warren Samuels (eds.), Blackwell Companion to the History of Economic Though, Oxford, Basil Blackwell, 2002.

Borx, C. (1991), «Promesas y límites del policy analysis en Estados Unidos», en Documentación Administrativa, n. ${ }^{\circ} 224-$ 225, octubre 1990-marzo 1991, pp. 167-194.

Boudreaux, D.J. y DiLorenzo, T.J. (1993), «The Protectionists Roots of Antitrust», en Review of Austrian Economics, vol. 6, n. ${ }^{\circ}$ 2, pp. 81-96.

BRENNER, R. (1995), «Sciences of Political Lies, or Governments and Markets of Ideas», en Advances in Austrian Economics, vol. 2B, pp. 345-369.

BuCHANAN, A. (2003), «The Making and Unmaking of Boundaries: What Liberalism Has to Say», en Allan Buchanan y Margaret Moore (eds.), States, Nations and Borders. The Ethics of Making Boundaries, Cambridge, Cambridge University Press, pp. 231-272.

Calhoun, J. (1851), Disquisición sobre el gobierno, Madrid, Tecnos, 1996.

COASE, R. (1994), «El faro en la economía», en Ronald Coase, La empresa, el mercado y la ley, Madrid, Alianza Editorial, pp. 187-205.

Cordato, R. (2004), «Toward an Austrian Theory of Environmental Economics», en Quarterly Journal of Austrian Economics, vol. 7, n. ${ }^{\circ}$ 1, Spring, pp. 3-16. 
Creveld, M. van (1999), The Rise and Decline of the State, Cambridge, Cambridge University Press, pp. 242-258.

Cuervo García y SAndulli, F.D. (2003), «Creación empresarial y dominio del mercado: El caso del Departamento de Justicia de los Estados Unidos contra Microsoft», en Información Comercial Española, n. ${ }^{\circ}$ 808, julio, pp. 217234.

DAviEs, S. (2002), «Laissez-Faire Urban Planning», en David T. Beito, Peter Gordon y Alexander Tabarrok (eds.), The Voluntary City: Choice, Community and Civil Society, Ann Arbor, The Independent Institute, pp. 18-46.

DiLorenzo, T.J. (1992), «The Myth of Predatory Pricing», en Policy Analysis, n. ${ }^{\circ}$ 169, February 28.

Etcoff, N. (2000), La supervivencia de los más guapos, Madrid, Debate.

Flew, A. (1996), «Social Democracy and the Myth of Social Justice», en Hardy Bouillon (ed.), Libertarians and Liberalism. Essays in Honour of Gerard Radnitzky, Aldershot, Avebury, pp. $170-183$.

Formaini, R. (1990), The Myth of Scientific Public Policy, New Brunswick,Transaction.

Friedman, D. (1977), "A Theory of the Size and Shape of Nations», en Journal of Political Economy, vol. 85, n. ${ }^{\circ}$ 1, pp. 59-77.

GARSON, D.G. (1992), «De la ciencia de políticas al análisis de políticas: Veinticinco años de progreso», en Luis F. Aguilar Villanueva (ed.), El estudio de las políticas públicas, México, Porrúa, pp. 149-179.

Goldhamer, H. (1978), The Adviser, New York, Elsevier.

GOUlDNER, A. (1985), El ascenso de los intelectuales y el ascenso de la nueva clase, Madrid, Alianza editorial.

Hardin, G. (1989), «La tragedia de los comunes», en Herman Daly (ed.), Economía, ecología y ética: Ensayos hacia una economía en estado estacionario, México, FCE. 
HAYEK, F.A. (1937), El nacionalismo monetario y la estabilidad internacional, Madrid, Aosta, 1996, pp. 39-49.

- (1988), Derecho, legislación y libertad. Vol. II: El espejismo de la justicia social, Madrid, Unión Editorial.

- (1992), La fatal arrogancia: Los errores del socialismo, Madrid, Unión Editorial, pp. 173-190.

- (2003), La contrarrevolución de la ciencia, Madrid, Unión Editorial.

Hazlitt, H. (1979), Los fundamentos de la moral, Buenos Aires, Fundación Bolsa de Comercio de Buenos Aires, pp. 391416.

- (1996), La economía en una lección, Madrid, Unión Editorial.

Holcombe, R. (2004), «Government : Unnecessary, but Inevitable», en Independent Review, vol. VIII, n. ${ }^{\circ} 3$, Winter 2004, pp. 325-342.

Hoppe, H.-H. (1990), «Marxist and Austrian Class Analysis», en Journal of Libertarian Studies, vol. 9, n. ${ }^{\circ}$ 2, Fall, pp. 79-93.

- (1996), «Falacias de la teoría de los bienes públicos y la producción de seguridad», en Libertas, n. ${ }^{\circ} 24$, mayo.

- (2001), Democracy: The God that Failed, New Brunswick, Transaction. Existe traducción castellana: Monarquía, democracia y orden natural (Madrid, Ed. Gondo, 2004).

- (2002), «Natural Order, the State, and the Inmigration Problem», en Journal of Libertarian Studies, vol. 16, n. ${ }^{\circ} 1$, Winter, pp. 75-97.

- (ed.) (2003), The Myth of National Defense, Auburn, Ludwig von Mises Institute.

Huerta De Soto, J. (1994), «Derechos de propiedad y gestión privada de los recursos de la naturaleza», en Jesús Huerta de Soto, Estudios de Economía Política, Madrid, Unión Editorial, pp. 229-249.

- (2000), La escuela austriaca, Síntesis, Madrid, pp. 13-32. 
- (2002), «El economista liberal y la política», en Jesús Huerta de Soto, Nuevos estudios de economía política, Madrid, 2002, pp. 163-192.

- (2004), «La teoría de la eficiencia dinámica», en Procesos de Mercado, vol. I, n. ${ }^{\circ} 1$, primavera, pp.11-71.

HÜlsmanN, J.G. (2000), «A Realistic Approach to Equilibrium Analysis», en Quartely Journal of Austrian Economics, vol. 3, n. ${ }^{\circ}$ 4, Winter, pp. 3-51.

IKEDA, S. (1997), Dynamics of the Mixed Economy, London, Routledge.

JaCOBS, J. (1986), Las ciudades y la riqueza de las naciones, Barcelona, Ariel.

Jouvenel, B. de (1998), Sobre el poder. Historia natural de su crecimiento, Madrid, Unión Editorial, pp. 201-219.

- (2000), La soberanía, Granada, Comares, pp. 153-176.

KeRn, F. (1955), Derechos del rey y derechos del pueblo, Madrid, Rialp.

KeYnes, J.M. (1988), «Las posibilidades económicas de nuestros nietos», en John Maynard Keynes, Ensayos de persuasión, Crítica, Barcelona.

Kirzner, I.M. (1989), «Antitrust Reform: Predatory Practices and the Competitive Process», en Review of Austrian Economics, vol. 3, n. $^{\circ} 1$, pp. 61-74

- (1999), «Los objetivos de la política antitrust: una crítica», en Información Comercial Española, n. ${ }^{\circ} 775$, diciembre 1998enero 1999, pp. 67-77.

KukAthas, C. (2003), «The Cultural Contradictions of Socialism», Social Philosophy and Policy, vol. 20, n. ${ }^{\circ} 1$, pp. 165-190.

Mirowski, P. (1989), More Heat Than Light, New York, Cambridge University Press.

Mises, L. von (2002), Crítica del intervencionismo, Madrid, Unión Editorial.

Oppenheimer, F. (1926), The State, New York, Free Life Editions, 1975. 
Peters, B.G. (1999), La politica de la burocracia, México, Fondo de Cultura Económica.

PolanyI, K. (dir.) (1976), Comercio y mercado en los imperios antiguos, Barcelona, Labor.

RothbARD, M.N. (1956), «Toward a Reconstruction of Utility and Welfare Economics», en Hans Sennholz (ed.), On Freedom and Free Enterprise: Essays in Honor of Ludwig von Mises, Princeton, D. Van Nostrand.

- (1961), Man, Economy and State, Ludwig von Mises Institute, Auburn, 1993, p. 19.

- (1970), Power and Market, Kansas City, Sheed Andrews and McMeel, pp. 10-13.

- (1977), Strategies for A Libertarian Victory, Rothbard Caucus, Libertarian Party,

- (1978), For a New Liberty: The Libertarian Manifesto, New York, Collier Books, pp. 54-69.

- (1979), «The Myth of Efficiency», en Mario Rizzo (ed.), Time, Uncertainty and Disequilibrium, Lexington, D.C. Heath, pp. 90-95.

- (1992), «How and How Not to Desocialize», en Review of Austrian Economics, vol. 6, n. ${ }^{\circ} 1$, pp. 65-77.

- (1994), The Case Against the FED, Auburn, Ludwig von Mises Institute.

- (1995a), La ética de la libertad, Madrid Unión Editorial, pp. 59-103.

- (1995b), Making Economic Sense, Auburn, Ludwig von Mises Institute, pp. 15-56.

- (2000), «Freedom, Inequality, Primitivism and the Division of Labor», en Murray N. Rothbard, Egalitarianism as a Revolt against Nature and other Essays, Auburn, Ludwig von Mises Institute. 
- (2002), «Milton Friedman Unraveled», en Journal of Libertarian Studies, vol. 16, n. ${ }^{\circ}$ 4, Fall, pp. 37-54.

Rustow, A. (1980), Freedom and Domination: A Historical Critique of Civilization, Princeton, Princeton University Press, pp. 150-175.

- (2004), Down with Primitivism: A Thorough Critique of Polan$y i$, en Paul Samuelson (1954), «The Pure Theory of Public Expenditure», en Review of Economics and Statistics, vol. 36, November, pp. 387-89.

- (1955), «A Diagrammatic Exposition of a Theory of Public Expenditure», en Review of Economics and Statistics, vol. 37, November, pp. 350-356.

Sechrest, L. (2003), «Private Provision of Public Goods: Theoretical Issues and Some Examples from Maritime History», Independent Institute Working Papers.

Simon, H.A. (1958), El comportamiento administrativo, Madrid, Aguilar.

Stanbury, W. y Thompson, F. (1995), «Toward a Political Economy of Government Waste: First Step, Definitions», en Public Administration Review, vol. 55, n. ${ }^{\circ}$, September/October, pp. $418-427$.

Tilly, C. (1985), «War Making and State Making as Organized Crime», en Peter Evans, Dietrich Rueschemeyer y Theda Skocpol (eds.), Bringing the State Back In, Cambridge, Cambridge University Press.

Torgerson, D. (1999), «El análisis de políticas públicas y la vida pública: ¿La restauración de la phronêsis?», en James Farr, John S. Dryzek y Stephen T. Leonard (eds.), La ciencia politica en la historia, Madrid, Istmo, pp. 289-324.

Wolf (Jr.), C. (1995), Mercados o gobiernos. Elegir entre alternativas imperfectas, Madrid, Instituto de Estudios Fiscales.

Zerzan, J. (2001), Futuro primitivo y otros ensayos, Numa, Valencia. 